\title{
A Method of Predicting Malignant Neoplasms of the Female Genital Area
}

\author{
A M Ershov* and Yu V Ershova \\ Yaroslavl State Medical University" Ministry of Health of Russia, Russia \\ *Corresponding author: Alexey M Ershov, Yaroslavl State Medical University" Ministry of Health of Russia, Russia
}

$\begin{array}{lll}\text { ARTICLE INFO } & & \text { ABSTRACT } \\ \begin{array}{l}\text { Received: } \\ \text { Published: December 07, } 2020\end{array} & & \begin{array}{l}\text { Citation: A M Ershov, Yu V Ershova. A Method of Predicting Malignant Neoplasms of the } \\ \text { Female Genital Area. Biomed J Sci \& Tech Res 32(4)-2020. BJSTR. MS.ID.005270. }\end{array}\end{array}$

\section{Introduction}

Summary: Using a multivariate statistical analysis of open questionnaire screening of conditionally healthy women and women with female malignant tumors, identify their statistically significant predictors, estimate their sensitivity and specificity, calculate the prediction factor and create a computer program based on it that automates the processing of questionnaires and form risk groups for regular follow-up without the participation of a doctor via the Internet, or on the computers of wives FIR consultations.

Scientific Novelty: For the first time, based on the use of multivariate statistical ROC - analysis of 82 questions and answers of women surveyed [1], we identified 18 statistically reliable predictors of malignant neoplasms ( $\mathrm{MN}$ ) of the female genital area, which were used to calculate the prognostic risk factor for MN of the female reproductive system (patent for invention №2018146754 dated 04.04.2019). The AUC $=0.902$ interval (sensitivity of $72.8 \%$, specificity of $95 \%$ ), which corresponds to the high quality of the prediction of the screening questionnaire method, which allowed us to create a computer program for the formation of risk groups without the participation of doctors and recommend it for use in the personal workplace computer system primary physicians and in the clinical examination of the population [2-4].

\section{Materials and Methods}

The work was done in 2 stages. Stage 1 (open survey) on the basis of statistical data processing of 226 women. The first group: patients with malignant neoplasms of the female genital area (125), the second group: conditionally healthy women (101). The questionnaire included 82 points: 19 open questions and 63 with a choice of answer. Stage 2 (blind questioning) 120 women who applied to antenatal clinic. The questionnaire included previously identified 18 predictors. A multifactor model was created, during the development of which, besides the survey data, materials from the patient's history of patients and histological data were used. Data analysis was performed using Statistica 10.0 and MedCalc 12.7.0.

\section{Results}

A. Stage 1: A ROC analysis of the personal data was performed and 18 significant predictors of female genital mutilation were identified. Based on them, a formula for calculating the prognostic coefficient (PC) of the risk of developing female genital area with a sensitivity of $72.8 \%$ and a specificity of $95 \%$ has been derived. hospital sites.

B. Stage 2: as a result of a closed survey of 120 women for 18 predictors, 70 were at risk, of whom 47 (67\%) had female genital mutilation. 50 women were in the group of conditionally healthy, of which $45(90 \%)$ were healthy, and $5(10 \%)$ had MN. After the ROC analysis, the sensitivity of the method was $72.8 \%$, and the specificity was $95 \%$.

For the first time, based on the application of multivariate statistical ROC analysis of 82 questions and answers of the surveyed women [5], we identified 18 statistically reliable predictors of female genital mutilation, which can be used to form risk groups:
a) $\operatorname{Age}(\mathrm{B})(\mathrm{p}<0.0001)$
b) Menstrual irregularities (MCI) $(\mathrm{p}=0.0011)$
c) Late onset of sexual activity (LSP) $(p=0.0002)$ 
d) Lifetime IUD (IUD) $(\mathrm{p}=0.0164)$

e) Active lifestyle with a negative coefficient (AOI) ( $\mathrm{p}=$ 0.0576)

f) History of abortion $(\mathrm{Ab})(\mathrm{p}<0.0001)$

g) Presence of ruptures of the cervix during labor (PmShM) $(\mathrm{p}=0.0006)$

h) Presence of uterine fibroids $(\mathrm{MM})(\mathrm{p}=0.0231)$

i) Work associated with heavy physical labor (TFT) ( $\mathrm{p}=$ 0.0023 )

j) Decrease in body weight before diagnosis (BMT) ( $p$ $<0.0001)$

k) Long-term residence in military camps, air defense (air defense) troops ( $p=0.0086)$

l) Problems with conceiving a child (FFD) $(\mathrm{p}=0.0057)$

m) Stress, psychological overload, experiences (SPP) (p = $0.0001)$

n) Bleeding from the genital tract before diagnosis (PPC) ( $p$ $<0.0001$ )

o) Presence of diabetes mellitus (DM) $(p=0.0003)$

p) Presence of diseases of the cardiovascular system (CVD) $(\mathrm{p}<0.0001)$

q) Presence of breast cancer in relatives (breast cancer in P) $(\mathrm{p}=0.0007)$

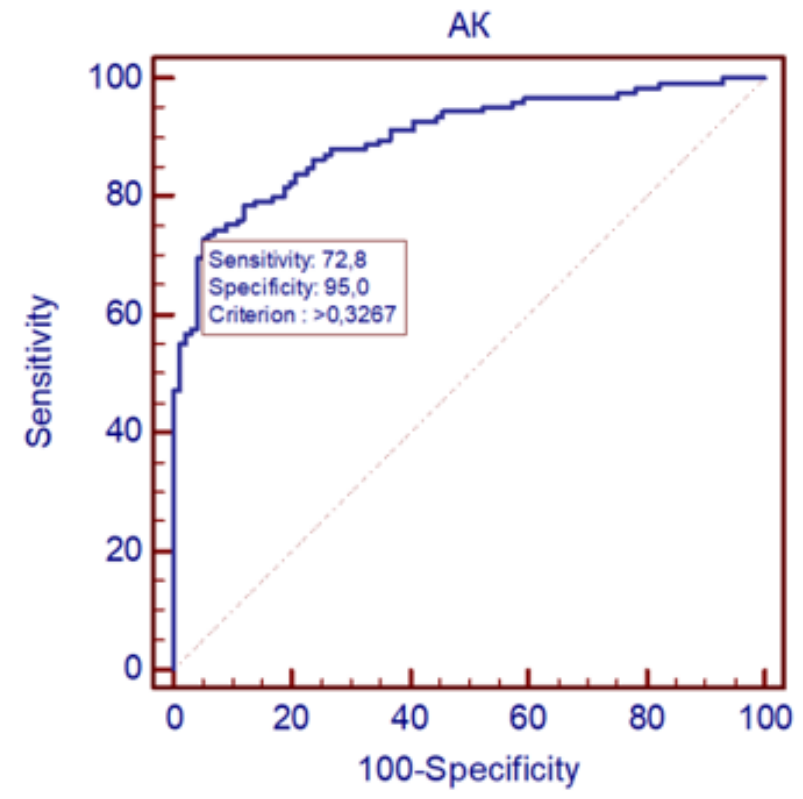

Figure 1. r) The presence of cancers of other localization in relatives (DR in P) ( $p=0.0135)$. The level of statistical significance is very high because $p \leq 0.0001$. The area under the ROC curve was 0.902 ; standard error 0.0199 ; the percentage of correctly classified cases is $72.8 \%$ (it says that in 73 cases we will have confirmation of female genital malignancy). The criterion for the value and coordinates of the ROC curve are all values> 0.3267 with a sensitivity of $72.8 \%$ and a specificity of $95 \%$. These indicators reflect the chances of making a correct diagnosis of the disease in sick and healthy people. Sensitivity is defined as the proportion of patients who actually have the disease among those who test positive. Specificity is defined as the proportion of people who are free of the disease among those who test negative [6].

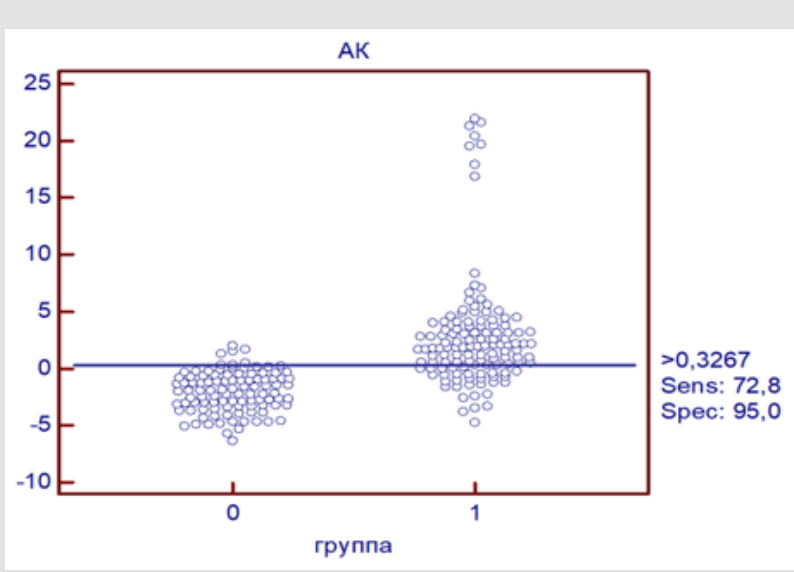

Figure 2.

\section{Conclusion}

a) A multifactorial statistical ROC - analysis of 82 questions and answers of the interviewed women allowed us to identify 18 statistically reliable predictors of female genital area in which it is possible to scientifically form risk groups for regular preventive measures with certain examinations.

b) The completed developments allow to create a computer program for automated processing of profiles on the formation of risk groups of MN of the female genital area and clinical supervision. The introduction of a screening questionnaire over the Internet with subsequent computer processing of the results without the direct involvement of doctors will increase the coverage of the female population of the Russian Federation activities related to the prevention of malignant neoplasms of the female genital area. It can free up time for physicians to receive primary patients, make it easier for them to create a database of survey results via the Internet from a large contingent of women, and also increase oncological vigilance among the female population of the Russian Federation. 


\section{References}

1. Davydov MI, Axel EM (2011) Ryazhenov V V, Gorokhova SG, 2011; Chissov V G, Starinskiy V V, Petrova G V, 2011.

2. Ed HELL Kaprina, VV Starinsky, GV Petrova (2015) The state of cancer care for the population of Russia in 2014. M: MNIOI them. P.A. Herzen branch of the Federal State Budgetary Institution "NMIRC" of the Ministry of Health of Russia, pp. 236.

3. Goryaeva A E, Petrov Yu A (2018) Screening for cervical cancer. International Journal of Applied and Fundamental Research 4: 171-175.

4. Meshkov AV, Vaziev IK, Gerasimova LI, Alieva G Sh, Vakhitov I Kh, et al. (2015) Questionnaire screening is a method of primary prevention of

ISSN: 2574-1241

DOI: $10.26717 /$ BJSTR.2020.32.005270

A M Ershov. Biomed J Sci \& Tech Res

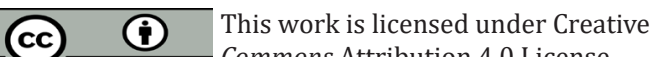

Submission Link: https://biomedres.us/submit-manuscript.php cancer (on the example of carcinogenic production). Modern problems of science and education 2: 1 .

5. Vesco KK, Whitlock EP, Eder M, Lin J, Burda BU, et al. (2011) Screening for cervical cancer: a systematic evidence review for the U.S. Preventive Services Task Force. Evidence Synthesis No. 86. AHRQ Publication No. 11-05156-EF-1. Rockville, MD: Agency for Healthcare Research and Quality; 2011.

6. Frederiksen ME, Lynge E, Rebolj M (2012) What women want. Women's preferences for the management of low-grade abnormal cervical screening tests: a systematic review. BJOG: An International Journal of Obstetrics and Gynaecology 119(1): 7-19.

$\begin{array}{ll}\text { BIOMEDICAL } & \text { Assets of Publishing with us } \\ \text { RESEARCHES } & \text { - Global archiving of articles } \\ \text { - Immediate, unrestricted online access } & \text { - Rigorous Peer Review Process } \\ & \text { - Authors Retain Copyrights } \\ \end{array}$

